\title{
Treatment of Meat Industry Wastewater Using Electrochemical Treatment Method
}

\author{
José Pinedo-Hernández, ${ }^{a, b, *}$ Yeison Núñez, ${ }^{a}$ Isaac Sánchez ${ }^{a}$ \\ and José Marrugo-Negrete ${ }^{a, b, *}$ \\ ${ }^{a}$ University of Córdoba, Faculty of Basic Sciences, Department of Chemistry, Water, Applied \\ and Environmental Chemistry Group, Monteria, Colombia \\ ${ }^{b}$ Laboratory of Toxicology and Environmental Management, University of Córdoba, \\ Montería, Colombia
}

Received 9 March 2015; accepted 23 August 2015

\begin{abstract}
In this work, electrocoagulation (EC) was used to treat meat industry (frigorific) wastewater. Effects of EC process variables such as distance between electrodes and potential on the removal efficiency of chemical oxygen demand (COD), were examined. Two factors with three levels response surface design coupled with response surface methodology (RSM) were employed to optimize the EC process variables. Second order polynomial models were developed for the responses and three dimensional (3D) response surface plots were used to study the interactive effects of the process variables on the EC efficiency. Experimental results showed that EC treatment, using a potential of $40 \mathrm{~V}$ and electrodes with a $3 \mathrm{~cm}$ gap between them, presented a COD removal of over $90 \%$ for the meat industry wastewater.
\end{abstract}

Keywords: Meat industry wastewater, Electrocoagulation, response surface methodology (RSM).

\section{Introduction}

Meat industry effluents (mostly from refrigerators) are characterized by high outflows and concentrations of organic matter composed mainly of fat, protein and cellulose. These, can be expressed by their chemical oxygen demand (COD) and biological oxygen demand (BOD), which reach high concentrations, varying depending on the number of animals slaughtered daily, animals diet and byproduct seen during the process [1-3]. In Colombia, 99\% of these establishments do not have an adequate system for wastewater treatment. 93\%

\footnotetext{
*Corresponding author. E-mail address: josejph@hotmail.com, joseluismarrugo@gmail.com.
} 
discharge their wastewater directly to a body of water, sewers or open field. $84 \%$ of the rumen contents are poured directly into water bodies or in the environment. 33\% do not make any use whatsoever of the blood produced during the processes of slaughter and dressing. These policies generate a health and environmental impact over $70 \%$ of the Colombian population [4-5].

Current need to comply with increasingly stringent environmental regulations promotes research and development of new technologies that allow efficient utilization, conservation and recovery of water resources. In recent years, an electrochemical method named electrocoagulation has attracted significant attention for wastewaters treatments due to their easy operation, less amount of added chemicals, lower production of sludge and no representative co pollution, etc. [6-9]. The aim of this work was to evaluate the electrocoagulation process of COD removal from meat industry wastewater at different conditions of potential and distance between electrodes, optimizing the conditions of maximum removal efficiency by response surface methodology (RSM). The obtained results will be helpful for the implementation of EC process in industrial level with lower environmental impact.

\section{Materials and methods \\ Wastewater}

Meat industry wastewater was collected from the local industry (frigorific), Monteria, Colombia. The characteristics of meat industry wastewater are determined by the dichromate method based on the standard methods of the American Public Health Association (APHA, 2012). The meat industry wastewater had a Chemical Oxygen Demand (COD) of $4216 \pm 75 \mathrm{mg} / \mathrm{L}$ and $\mathrm{pH}$ of 7.4 .

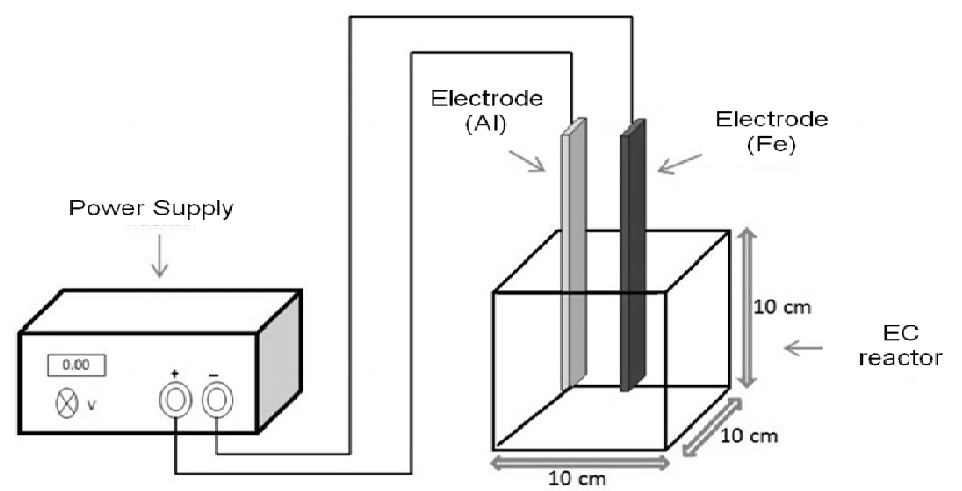

Figure 1. Schematic diagram of the electrochemical reactor.

\section{Experimental setup}

The experimental set up used in this study is shown in Fig. 1, which mainly consisted of a $1200 \mathrm{~mL}$ cell used as a reactor to hold a sample of $1000 \mathrm{~mL}$. Iron (Fe) and aluminum (Al) plates of $0.25 \mathrm{~cm}$ thickness $\times 2.5 \mathrm{~cm}$ width $\mathrm{x} 15 \mathrm{~cm}$ height were used as electrodes. The total effective surface area of electrodes was $22.6 \mathrm{~cm}^{2}$. The potential was maintained constant by means of a precision digital direct current power supply DC - PHYWE (0-50 V); electrolysis was carried out 
for $90 \mathrm{~min}$. All experiments were conducted in batch mode of operation and the $\mathrm{pH}$ of the wastewater was monitored. After the experiments, the electrodes were polished, washed with sulfuric 'acid $(0.10 \mathrm{M})$ and then rinsed with distilled water before each run. After applying current for the established period (i.e., after each batch experiment), the sample was stored in order to stabilize. After a settling period of $20 \mathrm{~min}$, the supernatant sample was collected to perform the analysis of COD. All the experiments were performed in three replicates to check the reproducibility.

\section{Experimental design}

Two factors three level response surface experimental design was used to optimize and investigate the influence of process variables such as potential and distance between electrodes on the treatment of meat industry wastewater using EC method. Process variables and their ranges were determined based on the single factor experimental analysis and are shown in Table 1. After selection of process (independent) variables and their ranges, experiments were established based on an experimental design $\left(3^{2}\right)$ which consists of 27 experiments. The aim of the experimental design and analysis was to define the effective factors, and to select the levels which give the maximum COD removal efficiency. The results were analyzed using Statgraphics Centurion XV.II software.

Table 1. Ranges of the independent variables and their levels.

\begin{tabular}{|c|c|c|c|c|}
\hline \multirow{2}{*}{ Variable (unit) } & \multirow{2}{*}{$\frac{\text { Factors }}{\mathrm{X}_{\mathrm{i}}}$} & \multicolumn{3}{|c|}{ Levels } \\
\hline & & -1 & 0 & 1 \\
\hline Distance between electrodes $(\mathrm{cm})$ & $\mathrm{X}_{1}$ & 1.0 & 3.0 & 5.0 \\
\hline Potential (V) & $\mathrm{X}_{2}$ & 20 & 30 & 40 \\
\hline
\end{tabular}

\section{Electrochemical energetic consumption}

The electrical energy consumption was calculated in terms of $\mathrm{kWh}$ [15].

$E(\mathrm{kWh})=\left(U^{*} I * t\right) / 1000$

where $\mathrm{U}$ is the cell voltage $(\mathrm{V}), \mathrm{I}$ is the current $(\mathrm{A}), \mathrm{t}$ is the time of $\mathrm{EC}(\mathrm{h})$.

\section{Results and discussions}

Two factors with three levels were used to evaluate and optimize the electrochemical treatment process variables on responses, such as, COD removal from meat industry wastewater. According to experimental design, a total of 27 batch experiments were carried out in triplicates and the results (mean values) are shown in Table 2. 
Table 2. Experimental design $\left(3^{2}\right)$ and its experimental results.

\begin{tabular}{|c|c|c|c|c|c|}
\hline & \multirow[b]{2}{*}{ Block } & \multirow[b]{2}{*}{ Potential (V) } & \multirow[b]{2}{*}{ Distance (cm) } & \multicolumn{2}{|c|}{ Removal efficiency $\%$} \\
\hline & & & & Anode (Fe) & Anode (AI) \\
\hline 1 & 1 & 20 & 1 & 71.3 & 86.1 \\
\hline 2 & 1 & 30 & 1 & 87.4 & 57.1 \\
\hline 3 & 1 & 40 & 1 & 83.0 & 67.6 \\
\hline 4 & 1 & 20 & 3 & 88.1 & 96.6 \\
\hline 5 & 1 & 30 & 3 & 96.1 & 92.7 \\
\hline 6 & 1 & 40 & 3 & 93.6 & 97.6 \\
\hline 7 & 1 & 20 & 5 & 89.7 & 88.3 \\
\hline 8 & 1 & 30 & 5 & 94.2 & 68.7 \\
\hline 9 & 1 & 40 & 5 & 93.1 & 94.3 \\
\hline 10 & 2 & 20 & 1 & 70.3 & 80.6 \\
\hline 11 & 2 & 30 & 1 & 86.8 & 73.1 \\
\hline 12 & 2 & 40 & 1 & 82.7 & 85.3 \\
\hline 13 & 2 & 20 & 3 & 88.5 & 97.8 \\
\hline 14 & 2 & 30 & 3 & 96.3 & 94.1 \\
\hline 15 & 2 & 40 & 3 & 93.9 & 98.2 \\
\hline 16 & 2 & 20 & 5 & 90.1 & 93.9 \\
\hline 17 & 2 & 30 & 5 & 94.3 & 96.6 \\
\hline 18 & 2 & 40 & 5 & 93.9 & 95.3 \\
\hline 19 & 3 & 20 & 1 & 72.0 & 87.0 \\
\hline 20 & 3 & 30 & 1 & 87.5 & 61.1 \\
\hline 21 & 3 & 40 & 1 & 83.0 & 72.2 \\
\hline 22 & 3 & 20 & 3 & 88.3 & 95.2 \\
\hline 23 & 3 & 30 & 3 & 95.6 & 92.3 \\
\hline 24 & 3 & 40 & 3 & 93.2 & 95.4 \\
\hline 25 & 3 & 20 & 5 & 89.9 & 89.4 \\
\hline 26 & 3 & 30 & 5 & 94.5 & 76.7 \\
\hline 27 & 3 & 40 & 5 & 92.4 & 94.6 \\
\hline
\end{tabular}

The results were analyzed using RSM, and the ANOVA table on the COD concentrations is given in Table 3. It can be seen that both linear and quadratic terms are effective factors on the optimization of COD concentration removal, due to their $\mathrm{p}$ values $(\mathrm{p}<0.05)$. Interaction terms have no statistical significant effect on the COD concentrations. In this second degree mathematical model, $\mathrm{R}^{2}$ (adjusted), which is a measure of the amount of reduction in the variability of $y$ obtained by using regression variables; $\mathrm{x}_{1}, \mathrm{x}_{2}$ and $\mathrm{x}_{2}{ }^{2}$ is $78.1 \%$ ( $\mathrm{Al}$ ) and $79 \%$ $(\mathrm{Fe})$ [11-12]. The estimated regression coefficients of linear and quadratic terms of the factors are given in Table 4. The remaining percentage of the total variation is explained by setting a mathematical model and it shows that the mathematical model with coded values is appropriate and acceptable. The mathematical model is obtained as follows:

Aluminum

$y_{1}=206.794+22.1125 x_{1}-10.4604 x_{2}-4.6541 x_{1}^{2}+0.1558 x_{2}^{2}+0.3062 x_{1} x_{2}$ 


$$
\begin{aligned}
& \text { Iron } \\
& y_{2}=89.9014+19.058 x_{1}-2.09 x_{2}-2.317 x_{1}^{2}-0.042 x_{2}^{2}+0.039 x_{1} x_{2}
\end{aligned}
$$

\begin{tabular}{|c|c|c|c|c|c|c|c|c|c|c|}
\hline Source & $D F$ & & Sum of squ & ares & Mean squ & sare & $F$ & & $P$ & \\
\hline & Al & $\mathbf{F e}$ & Al & $\mathbf{F e}$ & Al & $\mathbf{F e}$ & Al & $\mathbf{F e}$ & Al & $\mathbf{F e}$ \\
\hline$X_{I}$ : Distance & 1 & 1 & 273.375 & 365.040 & 273.375 & 365.040 & 5.64 & 22.28 & 0.0980 & 0.018 \\
\hline$X_{2}$ : Potential & 1 & 1 & 220.417 & 7.041 & 220.417 & 7.041 & 0.46 & 0.43 & 0.5483 & 0.558 \\
\hline$X_{I}^{2}$ & 1 & 1 & 693.161 & 170.509 & 693.161 & 170.509 & 14.31 & 10.41 & 0.0324 & 0.048 \\
\hline$X_{1} X_{2}$ & 1 & 1 & 150.063 & 2.722 & 150.063 & 2.722 & 3.10 & 0.17 & 0.1766 & 0.710 \\
\hline$X_{2}^{2}$ & 1 & 1 & 485.681 & 30.680 & 485.681 & 30.680 & 10.03 & 1.87 & 0.0506 & 0.264 \\
\hline Total error & 21 & 21 & 145.295 & 49.148 & 484.318 & 16.382 & & & & \\
\hline Total (corr) & 26 & 26 & 1.967 .992 & 625.140 & & & & & & \\
\hline $\mathrm{R}^{2}$ & 0.7811 & 0.7904 & & & & & & & & \\
\hline
\end{tabular}

Table 3. Variance analysis for removal efficiency.

Table 4. Estimated regression coefficients for COD concentrations.

\begin{tabular}{lcccccccc}
\hline \multirow{2}{*}{ Term } & \multicolumn{3}{c}{ Aluminium } & & & \multicolumn{3}{c}{ Iron } \\
\cline { 2 - 3 } \cline { 7 - 8 } & Coef. & SE Coef. & $\mathbf{P}$ & & Coef. & SE Coef. & P \\
\hline$b_{0}$ & 206.728 & 5.177 & 0.2732 & & 89.9014 & 3.012 & 0.2083 \\
$b_{1}$ & 22.1125 & 5.671 & 0.0987 & & 19.0580 & 3.299 & 0.0180 \\
$b_{2}$ & -10.456 & 5.671 & 0.5468 & & -2.090 & 3.299 & 0.5592 \\
$b_{11}$ & -4.6541 & 9.822 & 0.0321 & & -2.317 & 5.714 & 0.0477 \\
$b_{22}$ & 0.3062 & 9.822 & 0.0504 & & -0.042 & 5.714 & 0.2682 \\
$b_{12}$ & 0.1558 & 6.945 & 0.1766 & & 0.039 & & 4.040 & 0.7047 \\
\hline
\end{tabular}

Three dimensional (3D) response surface plots were constructed from the developed models in order to study the individual and interactive effect of the process variables on the responses and also used to identify the optimal condition of each factor to determine the maximum removal efficiency of COD (Fig. 2). The point indicated by the letter $\mathrm{P}$ for each graph shows removal $>90 \%$. From the results, it is found that the removal efficiency of COD increased with increasing the potential applied. This is attributed to the higher formation of $\mathrm{Fe}(\mathrm{OH})_{3}$ and $\mathrm{Al}(\mathrm{OH})_{3}$ species, which have strong affinity towards organic matters present in the wastewater to be treated, thus the removal efficiencies are increased [13-14]. Further, there is a negligible effect on removal efficiencies of COD. Although not tested, $\mathrm{pH}$ is an important operating factor influencing the performance of the electrochemical process. This can explained by the fact that, when the $\mathrm{pH}$ is in the range of 6-7 ( $\mathrm{pH}$ found for meat industry wastewater was of 7.4), the formation of $\mathrm{Fe}(\mathrm{III})$ and $\mathrm{Al}$ (III) species in the form of $\mathrm{Fe}(\mathrm{OH})_{3}$ and $\mathrm{Al}(\mathrm{OH})_{3}$ are seen, which increases the COD removal efficiency [15-17]. Distance between electrodes is one of the most important parameter that affects the electrocoagulation method to treat meat industry wastewater. From the results, it is found that the removal efficiency of COD increased with increasing the distance. This is attributed to the electrostatic field which is formed during the 
electrocoagulation process and depends on the distance between electrodes generating the metal ions produced by the anode, which main function is to destabilize loadings possessing contaminant particles present in water, neutralize the systems that keep the particles in suspension, allowing the formation of contaminant aggregates and initiating the coagulation process [18-19].

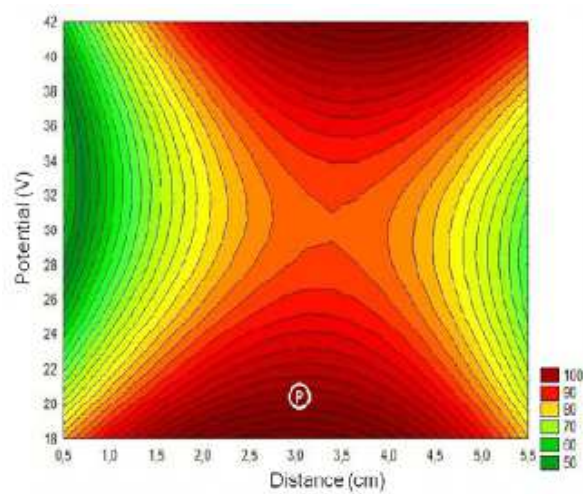

a)

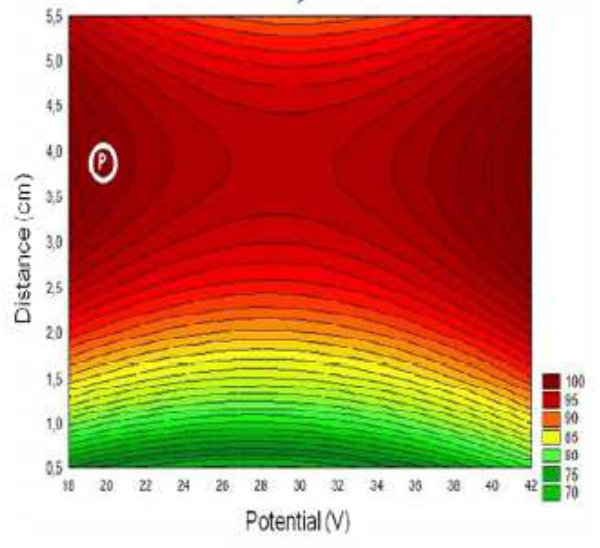

c)

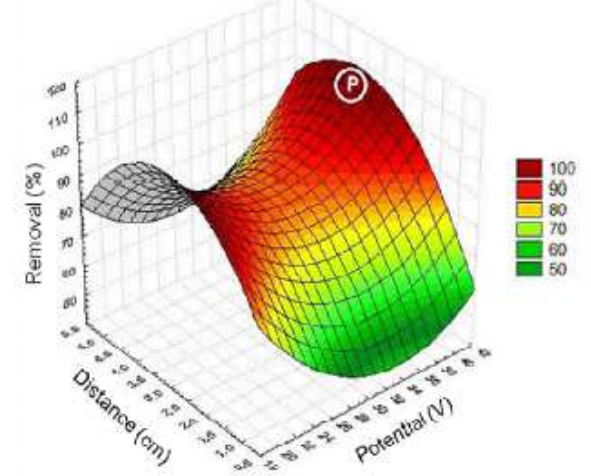

b)

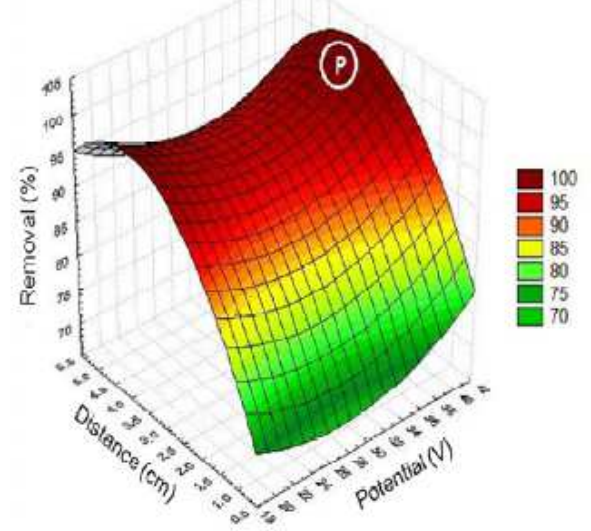

d)

Figure 2. 3D response surface contour plots for responses. a-b $(\mathrm{Al}), \mathrm{c}-\mathrm{d}(\mathrm{Fe})$.

The model generates the optimum values for the variables in order to obtain the maximum $\mathrm{Hg}$ removal efficiency as a function of potential and distance between electrodes (Table 5). Significant differences were not observed $(\mathrm{p}<0.05)$ when a point near to the maximum response is compared to the corresponding experimental value, which confirms that RSM can be used to optimize the process parameters.

Table 5. Optimum values of the process parameters for the maximum COD removal efficiency.

\begin{tabular}{lccccc}
\hline \multirow{2}{*}{ Parameter } & \multicolumn{2}{c}{ Aluminium } & & \multicolumn{2}{c}{ Iron } \\
\cline { 2 - 3 } \cline { 5 - 6 } & Optimum value & Experimental value & & Optimum value & Experimental value \\
\hline Removal (\%) & 98.9 & 97.6 & 3.0 & 98.6 & 3.5 \\
Distance (cm) & 3.2 & 40 & & 37.8 & 3 \\
Potential (V) & 39.6 & & & & 40 \\
\hline
\end{tabular}




\section{Economic evaluation}

The implementation of EC unit in large scale level mainly depends on the cost of the treatment process. In order to find out the economy of the proposed treatment method, the economic evaluation is made in optimum operating conditions and it is found that the energy required to treat wastewater by EC is $0.03 \mathrm{kWh}$ and given the price of Kwh in Colombia (\$349.7; \$US 0.13), the final cost for treatment is $\$ 10.49$ for volume of solution $\left(0.001 \mathrm{~m}^{3}\right)$, the equivalent to 10490 $\$ / \mathrm{m}^{3}$ (3.99 $\left.\$ \mathrm{US} / \mathrm{m}^{3}\right)$. This result illustrates the economic feasibility of the proposed treatment in the on-field implementation, i.e., wastewater treatment plants (WTP's).

\section{Conclusions}

These results indicated that electrocoagulation process is an effective treatment method to treat meat industry wastewater (frigorific) in terms of removal efficiency with reasonable operating cost. The optimal operating conditions were found to be: potential (Al: $39.6 \mathrm{~V}$; Fe: $37.8 \mathrm{~V}$ ), distance (Al: $3.2 \mathrm{~cm}$; Fe: $3.5 \mathrm{~cm}$ ). Under identical conditions $(40 \mathrm{~V}, 3 \mathrm{~cm})$, the removal efficiency of COD was found to be $97.6 \%(\mathrm{Al})$ and $98 \%(\mathrm{Fe})$. Significant differences were not observed $(\mathrm{p}<0.05)$ between the COD removal using iron or aluminum as sacrificial electrode. This study is a first step in implementing systems with continuous electrocoagulation of meat industry wastewater.

\section{Acknowledgements}

The authors wish to thank the University of Cordoba, Montería-Colombia, Water, Applied and Environmental Chemistry Group, Laboratory of Toxicology and Environmental Management, University of Cordoba, Montería-Colombia.

\section{References}

1. Masse DI, Masse L. Canad Agricultural Eng. 2000;42:139-146.

2. Shahzad ZI, Sonia N, Muhammad RA, et al. Food Control. 2014;43:98-103.

3. Li F, Wichmann K, Otterpohl R. Sci Total Environ. 2009;407:3439-3449.

4. MINAMBIENTE y Sociedad de agricultores de Colombia. Guía ambiental para las plantas de beneficio del ganado. Bógota. 2002:1-35

5. Guerrero J, Ramirez I. Scientia Et Technica. 2004;26:199-204

6. Xiong YA, Strunk PJ, Xia H, et al. Water Res. 2001;35:4226-4230.

7. Alinsafi A, Khemis M, Pons MN, et al. Chem Eng Processing. 2005;44:461-470.

8. Emamjomeh MM, Sivakumar M. J Environ Manage. 2009;90:1663-1679

9. Harif T, Khai M, Adin A. Water Res. 2012;46:3177-3188.

10. APHA. 25th ed. New York: American Public Health Association, American Water Works Association, Water Pollution Control Federation; 2012.

11. Hines WH, Montgomery D.C. Probability and Statistics in Engineering and Management Science. 3rd ed. New York: John Wiley \& Sons; 1990. 
12. Montgomery DC. Design and analysis of experiments. Nebraska: John Wiley \& Sons; 2000.

13. Daneshvar N, Khataee AR, Ghadim ARA, et al. J Hazard Mater. 2007; 148:566-572.

14. Thirugnanasambandham K, Sivakumar V, Prakash Maran J. J Serb Chem Soc. 2014;79:743-7457.

15. Thirugnanasambandham K, Sivakumar V, Prakash Maran J. J Korean Chem Soc. 2014; 58:198-204.

16. Behbahani M, Alavi Moghaddam MR, Arami M. Desalination. 2011;271:209-218.

17. Gengec E, Kobya M, Demirbas E, et al. Desalination. 2012;286:200-209.

18. Holt P, Barton G, Mitchell C. Electrocoagulation as a Wastewater Treatment. The Third Annual Australian Environmental Engineering Research Event.1999.

19. Daneshvar N, Sorkhabi HA, Kasiri MB. J Hazard Mater. 2004;112:55-62. 